\title{
An issue for Wegner's theory about the conscious will: the Readiness Potential does not conclusively represent preparation for an action
}

Um problema para a teoria de Wegener sobre a vontade consciente: Potencial de Prontidão não representa a preparação para uma ação de maneira conclusiva

\begin{abstract}
The role of consciousness in the production of actions has received much attention from philosophy and neuroscience. Wegner (2002) claims that what he calls the conscious will plays no role in the causal production of human actions, and that it is just an illusion. I will argue that Wegner's claim is mistaken, because his defense of the alleged illusion rests on how he conceives of what the Readiness Potential (RP) represents in a key experiment-Libet's experiment-and this conception is mistaken. Therefore, Wegner has not offered a convincing reason to believe that humans are deluded about the way they produce their actions.
\end{abstract}

Keywords: conscious will, Readiness Potential, action, experience.

Resumo: O papel da vontade consciente na produção de ações tem recebido bastante atenção tanto da filosofia como da neurociência. Wegner (2002) afirma que o que ele chama de vontade consciente não desempenha nenhum papel na produção causal das ações humanas, e que a mesma é apenas uma ilusão. Será argumentado no presente artigo que a afirmação de Wegner está equivocada, porque a sua defesa da suposta ilusão está fundamentada em como ele concebe o que o Potencial de Prontidão representa em um experimento crucial-o experimento de Libet-e essa concepção está errada. Portanto, Wegner não oferece uma razão convincente para se crer que os seres humanos estão iludidos a respeito de como produzem suas ações.

Palavras-chave: vontade consciente, Potencial de Prontidão, ação, experiência.

\section{Introduction}

There is a lively debate in philosophy and neuroscience about the role of the so called conscious will in the production of action. Daniel Wegner $(2002$; 2008) aims to settle the debate by providing an explanation of the role of conscious will in the production of actions, which, according to him, is in fact just an illusion.

\footnotetext{
${ }^{1}$ Doutora em Filosofia pela Universidade de São Paulo, professora do Departamento de Filosofia da Universidade Federal do Mato Grosso, Cuiabá, MT, Brasil. Av. Fernando Corrêa da Costa, 2367, Departamento de Filosofia - ICHS, Boa Esperança, Cuiabá, MT, 78068-6oo, Brasil - bsorrentinom@gmail.com
} 
I disagree with Wegner, and in the next sections I will explain why there is not enough reason to accept this so called illusion. The discussion will be divided into three parts. In section 2, I will briefly discuss the reasons Wegner offers for believing that the conscious will is an illusion. I will argue that one of his theory's pillars is Libet's (et al. 1983) famous experiment, but that the experiment does not in fact grant support to Wegner's theory in the way he believes it does. In section 3, I will defend the claim that there is a conceptual problem about the crucial evidence for his claims. The problem is that the way in which the Readiness Potential ${ }^{2}$ (RP) is conceived-a key element in Libet's experiment-is not in accordance with new empirical data. Therefore, it must be revised. Wegner's The Illusion of Conscious Will (2002), nevertheless, is an extensive and complex investigation that I cannot fully discuss here. I will limit the present discussion to the main arguments that give grounds to his Theory of Apparent Mental Causation (TAMC), especially Libet's experiments. ${ }^{3}$ Finally, in section 4 , I will answer some objections that may arise from my arguments.

\section{Is the conscious will an experience or a cause?}

In short, Wegner (2002) develops a theory in which he tries to show that human agents interpret the experience of conscious will they have when they act as meaning that their conscious will caused their actions. According to Wegner, however, this is an illusion; unconscious mechanisms causally produce human action, and the experience of conscious will is not an experience of the real causes of action.

It is common to talk about conscious will as something that is experienced when we perform an action-actions feel willed or not, and this feeling of voluntariness or doing a thing "on purpose" is an indication of conscious will. It is also common, however, to speak of conscious will as a force of mind, a name for the causal link between our minds and our actions. One might assume that the experience of consciously willing an action and the causation of the action by the person's conscious mind are the same thing.

\footnotetext{
${ }^{2}$ The so called Readiness Potential is an electrical activity measured in the brain in the motor cortex and supplementary motor area, a negative shift of potential that precedes movements.

${ }^{3}$ Wegner discusses extensive empirical data in the remainder of his book that I will not discuss here. I will focus on the grounds for his theory.
} 
As it turns out, however, they are entirely distinct, and the tendency to confuse them is the source of the illusion of conscious will that this book is about. (WEGNER, 2002, p. 03)

Wegner accepts that we have the experience of conscious will, and denies that the conscious will is in fact the cause of our actions, or that the experience corresponds to such a cause. Wegner's theory focuses on showing that the experience of conscious will is not the experience of the production of the action, and that it is not a reason to believe that we consciously will our actions.

Since conscious will is not a common term in ordinary parlance and is not easily understood, ${ }^{4}$ my strategy will be to assume that by experience of conscious will Wegner means the experience that one consciously produces one's action, on purpose; perhaps the experience of a conscious mental state relevant to the action production. And by conscious will he means a conscious mental state that humans believe plays a role in the production of action, such as a conscious intention. One passage backs up my interpretation: "The new idea introduced here is the possibility that the experience of acting develops when the person infers that his or her own thought (read: intention, but belief and desire are also important) was the cause of the action" (WEGNER, 2002, p. 66).

The experience Wegner associates to purpose can be considered as similar to what Haggard and Clark (2003) call the Experience of Source of Action (ESA), "We normally experience our actions as flowing from a source, or reason for actions (HAGGARD; CLARK, 2003, p. 696)-with the distinction that the latter do not treat it as fostering an illusion. So I will follow their use of the term, because I believe it is clearer than conscious will. 5

\subsection{The reliability of the ESA put into question}

\footnotetext{
${ }^{4}$ The concepts used by Wegner constitute an issue in itself. Conscious will and experience of conscious will are not ordinarily used terms. There is a controversial discussion about whether such a thing as the will exists (O'SHAUGHNESSY, 1996). The will is a philosophical term that was used in the XVIII and XIX century, and what it may actually refer to has been a question for debate. This, nonetheless, is an issue that I do not intend to settle in this paper.

${ }^{5}$ I don't think that I can be accused of transforming the experience of conscious will into too much of a technical term, because in ordinary conversations we usually do not say such things as: "I consciously willed my calling him, and he picked up." So, conscious will seems to already be a technical term.
} 
Wegner believes that "[...] action and the feeling of doing are not locked together inevitably" (2002, p. 11). Since these come apart, Wegner suggests that they may be produced by separate systems (2002, p. 11), therefore, the ESA, allegedly, is not an experience of how we produce our actions. To make this clear, he shows that there are situations in which action and ESA come apart: (1) there is no ESA in some actions that seem to be willed; e.g., hypnosis, table turning, and automatisms. ${ }^{6}$ (2) There can be ESA when there is no action. The latter is what Wegner calls illusion of control. ${ }^{7}$

He presents these cases to show that the ESA can be detached from the production of action. Some actions are accompanied by it, while others are not. Thus, the experience is purportedly not an experience of anything that plays a causal role in the production of actions; since it does not accompany all actions, it could not play a causal role in all actions.

It could be said that Wegner also offers the argument that automatisms are the real deal. Roughly: since there are automatic processes by which humans produce actions, it makes more sense to think that there is just one kind of causal process to produce actions, not one for automatism and one for productions of actions in which we have the experience of conscious will. I will not discuss this argument here, but I would like to note that there is a clear distinction between automatisms and actions of which the agent has a conscious experience of producing: conscious experience. This may be a sign that there is in fact a difference in their productions. The argument put forward in this paper will help inform this discussion.

These arguments, however, show at the most that it may be possible that the ESA is produced separately from the production of actions. However, they do not provide reasons to believe that it is actually produced separately. Wegner seems aware of this, as he furthers his argument to show that the experience in question is actually produced separately from the production of actions.

Nahmias (2002) interprets Wegner as saying something similar to my interpretation: the module that produces the experience of

\footnotetext{
${ }^{6}$ We leave aside cases of brain damage-e.g. alien hand syndrome-since clearly something is wrong in those.

7 "[...] instances in which people have the feeling they are doing something when they actually are not doing anything” (WEGNER, 2002, p. o9).
} 
conscious will is separate from the one that causes behavior: "Most of the evidence discussed in the book is used by Wegner to demonstrate that the experience of will and the empirical will 'come apart often enough to make one wonder whether they may be produced by separate systems in the mind' (p. 11)" (NAHMIAS, 2002, p. 530).

\subsection{Where and when of the ESA is produced}

It is an important step in Wegner's argument to locate the anatomical source and timing of the feeling of doing ${ }^{8}$ in order to show that the ESA is produced separately from the mechanisms that produce action, and that it in fact fosters an illusion. The investigation of the anatomical source, nevertheless, is inconclusive. "In a sense, it is not clear that any studies of the sense of effort in movement can isolate the anatomical source of the experience of conscious will" (WEGNER, 2002, 44).

So, Wegner turns next to locating the ESA in time. Wegner's account of when the ESA occurs is focused on Libet's (et al. 1983, 1985) famous experiments. Roughly, the experiment that figures mainly in Wegner's argument compared the moment of the Readiness Potential (RP) onset $^{9}$ before a spontaneous ${ }^{10}$ finger, or wrist, movement to the moment subjects reported being aware of the urge to move ${ }^{11}$. These were also compared to the moment of the actual movement onset. Together, they resulted in a timeline of the production of action proposed by Libet.

In summary, Libet found that the RP onset was around $550 \mathrm{~ms}$ before the movement, while the awareness of the urge to move-what Wegner associates to the experience of conscious will ${ }^{12}$-was reported as having occurred only $200 \mathrm{~ms}$ before the movement onset. From this, Libet concluded that the brain starts preparing to move $350 \mathrm{~ms}$ before the agent is aware of her urge to move.

\footnotetext{
${ }^{8}$ Wegner uses this expression interchangeably with the experience of conscious will.

9 Electroencephalogram (EEG) was used to record the electric activity of the relevant brain area. The electroencephalogram is used to monitor the electrical activity in the brain, usually in the cortex.

${ }^{10}$ By spontaneous Libet means only that the movement was not preplanned by the subject and there was no time restriction for the movement imposed by the experiment's instructions.

${ }^{11}$ In the experiment Libet calls this the consciousness or awareness of the urge or intention to act, among other expressions-what I have been calling ESA.

${ }^{12}$ Wegner seems to use the term conscious will and conscious wanting interchangeably (WEGNER, 2002, p. 55) when discussing Libet's (1983) experiment.
} 
To Wegner this is enough to say that the ESA cannot be related to a relevant role in the production of actions, such as the one expected that conscious will should play. "The conclusion suggested by this research is that the experience of conscious will kicks in at some point after the brain has already started preparing for the action” (WEGNER, 2002, p 54). Hence, if the RP is the brain's preparation for the action, then the ESA is not the experience of the cause of action, because it occurs after the production of the action has already started.

The experiment allows Wegner to conclude that the late timing of the conscious experience cannot be associated to the cause of action, because if it did it would have to come before it, or at least simultaneously to the brain events relevant to the production of the action. Therefore, the production of action is independent of the experience, and the ESA is originated separately from the real mechanisms that produce actions.

I do not claim that Wegner does not bring other data into the discussion, but Libet's experimental results are the main and most significant data that Wegner offers in support of his conclusions about the moment of the conscious will in the timeline of the production of action. Wegner's Theory of Apparent Mental Causation (TAMC) is grounded on his conclusion that the ESA does not reflect how we produce our actions: "The processes described in this chapter rest on an important premise. They rely on the assumption that conscious will is an experience, not a cause. This means that the thoughts we attach to our actions are not necessarily the true causes of the actions [...]" (WEGNER, 2002, p. 95). What this means is that Wegner's theory relies on his argument that the ESA is produced separately from action and does not reflect how actions are produced; instead it springs an illusion of how actions are produced.

I am not alone in emphasizing the relevance of Libet's experiment to Wegner's argument. Nahmias (2002) also considers Libet's experiment important grounds for Wegner's claims. According to him, Wegner relies on three sources of evidence for his claims about the experience of conscious will: (1) Theory of Mind is a specialized module; (2) Libet's experiments; (3) Penfield and Delgado's clinical observations of brain stimulation. Nahmias dismisses (1) for being controversial (2002, p. 530531), and it could be said of (3) that Wegner himself accepts that these were not controlled experiments. 
Horgan also believes that Wegner's thesis depends heavily on his interpretation of Libet's experiments: "To my mind, the strongest of these arguments appeals to the standard construal of Libet-style experimental data [...]" (2010, p. 162). Additionally, others have noted the relevance of Libet's experiments to Wegner's theory (BOGEN, 2004; JACK; ROBBINS, 2004; PANKSEPP, 2004; CRANE, 2004; MELE, 2009, p. 31-32; CARLSON, 2010, p. 136). Therefore, I have offered reasons to accept that the argument in question is the most compelling evidence Wegner gives for accepting his claim that the experience of conscious will fosters and illusion. However, an assumption made by Libet in his experiments is problematic, and this will make clear that these experiments are not good grounds for Wegner's theory. The assumption in question is about what the RP represents.

\section{What is RP?}

Wegner's conclusion and theory relies heavily on the evidence provided by the Readiness Potential, which, on its turn, depends on how it is conceived. Wegner accepts Libet's interpretation of the RP as preparation for the action; preparation in this sense means the initiation of the causal production of the action. So, RP is conceived, roughly, as the electric potential that corresponds to the onset of the cerebral activity in the causal production of action; i.e., a reflection of the "preparatory cerebral process".

It did not escape Wegner's attention, however, that it was not clear what the RP represents in the production of action: "We don't know what specific unconscious mental processes the RP might represent. These processes are likely to be relevant in some way to the ensuing events, of course, because they occur with precise regularity in advance of those events" (WEGNER, 2002, p. 55). I assume that Wegner endorses Libet's functional conception of RP as the onset of the causal production of action, because even though Wegner claims that it is not quite clear what RP represents, he offers no alternative conception, and accepts Libet's interpretation of the experiment. 
If, however, one accepts that events are caused by previous events, ${ }^{13}$ then it makes sense to suppose that RP was probably caused by a previous event too. Why not call the event previous to the RP onset the first cause of action? I must make one thing clear about this point: I do not claim that Libet developed his conception of RP as preparation for action arbitrarily-this is a well-accepted conception, since RP is reliably observed before action. All I am claiming is that conceiving of RP as such is a conceptual presupposition of his experiment. What I will put into question in the next section is whether Libet's conceptual presupposition about the $\mathrm{RP}$, the association of RP with the preparation for the action, is correct.

\section{1. $R P$ is not preparation for the action}

At the time when Wegner wrote his book, there were few clues as to what the RP actually represents. Since the activity was observed before action, it became widely accepted that it represented preparation for the action, and Wegner seems to accept this conception. New evidence, however, suggests that the RP cannot be treated as preparation for the movement, and therefore does not reliably show that unconscious brain preparation to move precedes the ESA in the causal production of the action (SCHURGER et al., 2012; JO et al., 2013; SCHLEGEL et al., 2013; TREVENA; MILLER, 2010; HERRMANN et al., 2008).

This puts into question the idea that the ESA appears late in the timeline of the production of action or that it is produced separately from it. If the RP does not represent preparation to move, there is no evidence that the production of the specific action starts before the agent has any conscious experience of producing her action.

The interpretation of the experiment and its results rely on what $\mathrm{RP}$ is considered to be, i.e., how it is conceived. Interpreting experimental data is an important part of understanding its contributions. When

\footnotetext{
${ }^{13}$ This claim is not free of controversy. Davidson defended in his famous paper The Individuation of Events that the criterion for identity between events is: "events are identical if and only if they have exactly the same causes and effects. Events have a unique position in the framework of causal relations between events in somewhat the way objects have a unique position in the spatial framework of objects" (DAVIDSON, 1980, p.179). There are, however, theories of action that hold that the agent performs acts of willing, which are uncaused events; for instance, this is the position defended by Lowe (2008). The latter position is called volitionism and it faces the challenge of explaining how a willing can occur if it is not caused. In general, there is a tendency in the Philosophy of Action to consider that events are caused, given that the Causal Theory of Action is currently the orthodoxy of action explanation. Here, I follow this tendency.
} 
experimental protocols are designed, they are so based on previous information about the subject of investigation, and many times based on some conceptual and even ontological assumptions. For instance, an investigation about the properties of black matter does not make much sense if it is not accepted that black matter exists. Of course, probably all theories and experiments are based on assumptions of this kind, and these assumptions are usually based on good reasons; nonetheless, this does not mean that they cannot be questioned, or eventually be considered wrong in the face of new evidence. Good examples of the relevance of conceptual assumptions are current researches in neuroscience that draw conclusions about free will. Having a clear concept of free will and what it takes for a being to have free will is relevant to being able to design the experiment and interpret its results. Therefore, it is no different when considering Libet's experiment. It is important to know how the RP should be understood in order to be able to accurately interpret the results.

If Wegner wishes to claim that the conscious will appears "late" in the timeline of action because the RP is observed well before the subject reports she was aware of her intention to move (which Wegner seems to associate to the ESA), then it may not be enough to say that "we don't know what specific unconscious mental processes the RP might represent", but that they are likely releyant to action production. Just being observed regularly before action doesn't seem enough, for it leaves out the importance of covariation. Of course, empirical data is relevant to how the $\mathrm{RP}$ is understood; therefore, empirical data must be considered.

Is the RP observed when subjects do not act? There is room for clarification of the functional conception of RP. This being said, it is worth looking into these experiments that question the association of RP with the preparation of a specific movement. We will pay special attention to Schurger et al.'s (2012) experiment, because of its detail and completeness.

Schurger et al. (2012) have set out to investigate what RP represents by putting into question the "widely held assumption that the gradual increase in firing rate and electrical potential that precedes spontaneous movements does in fact reflect the goal-directed operations that cause those movements" (SCHURGER et al., 2012, p. E2904). The RP is a neural activity that reliably precedes self-initiated movement; however, Schurger et al. ponder whether it could reflect random fluctuation of activity. 
The first part of the experiment was to use a leaky stochastic accumulator $^{14}$ fed by noise ${ }^{15}$ to produce a model of what the experimenters called the neural decision, i.e., a threshold ${ }^{16}$ for the moment of onset of the movement preparation in Libet-style experiments. The idea is that preparation for the movement is only triggered when random noise crosses a threshold.

"The precise moment at which the decision threshold is crossed leading to movement is largely determined by spontaneous subthreshold fluctuations in neuronal activity" (SCHURGER et al., 2012, p. E2904). Thus, according to the model, RP is a neuronal activity that fluctuates, being possible to observe RP before action or when there is no action, and action initiation occurs only when the activity crosses a certain threshold. "According to our view, the motor system constantly undergoes covert fluctuations that bring it closer to or farther from threshold. These fluctuations are ongoing throughout the epoch [...]" (SCHURGER et al., 2012, p. E2905).

So, the RP fluctuation goes on for some time before any movement is initiated, according to the experimenters' model. The model was tested by testing the prediction the model makes about preparation for movement. Schurger et al. designed an experiment using EEG where participants were instructed to do the same task as the Libet task, except that there was the possibility that they may be interrupted by a random auditory click. It was called the Libetus interruptus task. If they were interrupted by the click, participants were to press the button as fast as they could; nonetheless, they were instructed to go through the trials in their regular pace, and to not try to beat the click.

The prediction was that, on the one hand, fast responses to a cue would be expected to happen late in trails if the activity reflects a mounting preparation for the movement over the course of the trial, as Libet believed

\footnotetext{
${ }^{14}$ Adding noise to a gradually accumulating signal yielded the leaky (because of the noise) stochastic accumulator model. In the model, the signal must cross a threshold for the movement to be initiated, and the threshold crossing varies in time for each trial because of the influence of the noise in the signal.

${ }^{15}$ Noise is, roughly, a random voltage fluctuation in neurons and networks of neurons.

${ }^{16}$ The initiation of movement, or decision threshold, is considered to be the moment when the preparation for a specific movement starts: "in the context of our model, the initiation of movement corresponds to a commitment to perform a given movement now-a threshold-crossing event that we refer to as the 'neural decision to move now'" (SCHURGER et al., 2012, p. E2905). The decision threshold was the crossing of the threshold that initiates the movement. This event is conceptually distinct from the conscious decision to move, which refers to the feeling of an urge or intention to move that may or may not play a causal role.
} 
it did. On the other hand, fast and slow reactions would be distributed equally in time over the course of the trial if the activity reflects ongoing spontaneous fluctuation (p. E2905), if their model was reliable. The experimenters' hypothesis was, therefore, the second possibility. Roughly, if the RP behaves the same in the experiment as the model predicts, then it is a good model for RP.

On the interrupted trials, the activity preceding the responses considered fast confirmed the experimenters' hypothesis. Since the clicks were unpredictable, the activity cannot reflect specific neural preparation for the movement. The randomness of the tone did not allow subjects to plan the movement. Therefore, fast responses are fast because the constant fluctuation of brain activity puts it closer to the threshold at that time.

Therefore, the role of the RP in the causal production of the movement, according to Schurger et al.'s model, is not directed to the production of a specific movement. On the contrary, since it results from spontaneous fluctuation, it is incidental.

The conception of neural decision is applied differently in the model endorsed by Schurger et al. from the one accepted by Libet (et al. 1983, 1985). Libet claimes that the neural decision happens at the onset of RP (550 ms before movement onset, and $350 \mathrm{~ms}$ before subjects' awareness of the urge to move), while Schurger et al. disagree, for the neural decision occurs after the observed onset of RP; they claim it is when the activity fluctuation crosses a threshold. "We propose that the brain uses the same machinery for decision making in this sort of task as it would in any decision-making task: a threshold applied to the output of a neural accumulator" (SCHURGER et al., 2012, p. E2905). Their experiment gives good reason to prefer their way of applying the concept. Taking into consideration the fact that RP fluctuation can be observed throughout the trials, it would be arbitrary to follow Libet and place the neural decision at the onset of RP. It is the threshold crossing that seems more reliably associated to the onset of the specific action.

The experimenters take their results to show that the RP could reflect spontaneous neural activity, contrary to the generally accepted understanding of RP as preparation for the action. The RP, therefore, should not be conceived as preparation for an action, but as general preparation. 


\subsection{Some possibilities}

Other experiments corroborate these findings (JO et al., 2013; SCHLEGEL et al., 2013; HERRMANN et al., 2008). For instance, Taverna and Miller (2010) developed a Libet style experiment in which participants heard a random tone after which they should decide to move or not to move (experiment 1). The experimenters found that there was no significant difference before trials in which the subjects decided to move from those in which they decided not to move. They conclude that the negativity preceding movements is related to involvement with the task, maybe attention, but not to preparation for a specific movement.

Taking these recent findings into consideration RP cannot be understood as preparation for a specific movement. It should be considered as random fluctuation of neuronal activity, reflecting general preparation at the most. Therefore, it is unwarranted to place the ESA in the timeline of action production as occurring after preparation for a specific action has started based on RP onset, contrary to what Libet's interpretation of his results suggests.

The experimenters seem to agree that the RP does not represent preparation for a specific movement; it probably represents general preparation or anticipation of a task. So, Wegner does not have grounds to conclude from Libet's experiment that the ESA is produced after, and separately, from the production of action. Nor can it be claimed that it is in fact irrelevant to action production, since it cannot be said that it appears after the production of the action has started based on the onset of the RP.

In fact, Schurger et al. suggest that the moment when the potential associated with action production crosses the decision threshold, $150 \mathrm{~ms}$ before movement onset coincides with, approximately, the time of subjects' awareness of the urge to move in Libet's experiment (2012, p. E2910). This constitutes evidence that the ESA may be the experience of a mechanism causally relevant to the production of action after all; perhaps the mechanism that triggers the onset of action, which could be called an intention. One must, nonetheless, be cautious when drawing conclusions form these results, for more investigation is surely needed before it can be claimed that there is substantial evidence in favor of such claims. 
I have argued that Wegner's TAMC depends on the hypothesis that the ESA is produced separately from the production of action. If one accepts that Wegner has not shown that there is in fact such separation, then his theory rests on thin ground. I believe that the recent studies that investigate what the RP represents show that Wegner has not provided enough evidence to conclude that there is such separation. The onset of the movement appears to occur after the onset of the RP, when the activity crosses a threshold. If Schurger et al. are correct and the threshold crossing coincides with the reports of awareness of wanting to move-the ESA-what could it mean?

It would be hasty to accept that this is the case without further investigation. Probably more data is necessary in order to evaluate if the hypothesis in question is correct. However, if it is correct it does not necessarily mean that the so called conscious will initiates action; I believe that Wegner is correct about this. Other explanations are available for the temporal coincidence. It may be that reaching the threshold produces the experience. Perhaps enough activity to cross the threshold leads to amplification of the activity to other brain areas-which would broadcasts information about the movement-and the amplification produces the experience (BAARS, 1988; DEHAENE et al., 2006). The experience could play a relevant role in the production of action that does not have to be of action initiation; such as directing attention to the movement, or being a part of control mechanisms (HAGGARD; CLARK, 2003).

\section{Problems}

One could object that the presented experiments may not be the last word about RP. What if neuroscience uncovers new evidence that supports Wegner's understanding of RP? I do not believe that the last word about the RP has been said. It is probable that further research will bring to light new evidence about it and about other processes in the production of actions; nonetheless, I do not wish to guess what those may be, for that is an empirical question, but the evidence we have at the moment suggests that RP is less specific to action preparation than Wegner accepts. In order to sustain that RP is specific to the preparation of action, I believe it would have to be shown that there is a particular relation between the RP and the action preparation that only occurs in 
relation to the action preparation. Only further discoveries can tell us if such relation exists, the evidence at the moment speaks otherwise.

It could also be asked whether I am proposing that the experience of the conscious will corresponds to the cause of action, and what would its role be in the production of action. The experience of conscious will is a term hard to define because conscious will is hard to define, so I will take it to mean here what Wegner takes it to mean, roughly, the conscious experience that we cause our actions, purposively-what I have been calling ESA.

I follow Wegner in accepting that humans have an experience of producing their actions, ESA; however, I have argued that Wegner has not given a convincing reason to accept that the experience produces an illusion about how actions are produced, because he has not shown that the ESA is produced separately from what he claims are the "real" mechanism that cause action. Therefore, it is possible that the experience in question is the conscious experience of a mechanism-it could be called an intention-causally relevant to the production of action.

It is even possible to ponder whether the conscious experience of producing our actions has a role itself in the production of actions, for it would be strange to consider that humans have conscious experiences if they do not serve any relevant function. This is, however, the subject for further discussion.

I must add that I do not mean to claim that human agents never act automatically, or that human action can never be produced in a way that the agent has no conscious experience of its production. Perhaps, agents are conscious of a mechanism that is causally relevant to the production of action in some actions, but not for others. Thus, the ESA would be lacking in the latter cases. I am not claiming that we necessarily have a conscious experience of the production of action; I am just claiming that when we do have this experience, there aren't good enough reasons to believe that it fosters an illusion about how we produce our actions.

\section{Conclusion}

Wegner argues the claim that our Experience of Source of Action, what he calls the experience of conscious will, is mistaken, and contributes to an illusion. The main argument discussed here relies on Libet's 
experiments, which leads Wegner to conclude that the experience in question appears late in the timeline of the production of actions. However, since this conclusion is grounded on a belief about the role that the RP has in the production of action, I have surveyed experiments that bring into question the RP's alleged role and questioned its functional conception. Therefore, I have claimed that Wegner has not offered good reasons to accept that the experience of conscious will fosters an illusion.

\section{Acknowledgements}

This paper was made possible by grants 2011/21030-o and 2014/02558-1, São Paulo Research Foundation (FAPESP). I would like to thank Katja Alice Behrens, Josh Turkewitz, Eduarda Calado, Raquel Krempel, and Larissa Gondim for their comments on previous versions of this paper.

\section{References}

BAARS, B. A cognitive theory of consciousness. New York: Cambridge University Press, 1988.

BOGEN, J. E. "The illusion of conscious will: Affective or cognitive?” In: Précis of the illusion of conscious will. Behavioral and Brain Sciences, 27(5) (2004), p. 12-13.

CARLSON, S. M. “Development of conscious control and imagination”. In: BAUMEISTER, R.; MELE, A.; VOHS, K. (Eds.). Free will and consciousness: How might they work? Oxford: Oxford University Press, 2010, p. 135-152.

CRANE, T. "Review of Mind Time by Benjamin Libet”. In: TLS, January 2005.

DEHAENE, S.; CHANGEUX, P.; NACCACHE, L.; SACKUR, J.; SERGENT, C. "Conscious, preconscious, and subliminal processing: a testable taxonomy”. Trends in Cognitive Science, 10(5) (2006), p. 204-2011.

DAVIDSON, D. “Individuation of action”. In: DAVIDSON, D. Essays on Actions and Events. Oxford: Oxford University Press, 1980 [1969], p. 163-18o.

DELGADO, J. M. Physical control of the mind: Towards a psychocivilized society. New York: Harper and Row, 1969.

HAGGARD, P.; CLARK, S. "Intentional action: Conscious experience and neural prediction. Consciousness and Cognition, 12(4) (2003), p. 695-707. 
1044 | Veritas | Porto Alegre, v. 63, n. 3, set.-dez. 2018, p. 1029-1045

HERRMANN, C. S.; PAUEN, M.; MIN, B.; BUSCH, N. A.; RIEGER, J. W. “Analysis of a choicereaction task yields a new interpretation of Libet's experiments”. International Journal of Psychophisiology, 67(2) (2008), p. 151-157.

HORGAN, T. "The phenomenology of agency and the Libet results". In: SINNOTARMSTRONG, W.; NADEL, L. (Eds.). Conscious will and responsibility. Oxford: Oxford University press, 2010, p. 159-172.

JACK, A. I; ROBBINS, P. “The illusory triumph of machine over mind: Wegner's eliminativism and the real promise of psychology". In: Précis of the illusion of conscious will. Behavioral and Brain Sciences, 27(5) (2004), p. 17-18.

JO, H.; HINTERBERGER, T.; WITTMANN, M.; BORGHARDT, T. L.; SCHMIDT, S. "Spontaneous EEG fluctuations determine the Readiness Potential: Is preconscious brain activation a preparation process to move?”. Experimental Brain Research, 231(4) (2013), p. 495-500.

LIBET, B.; GLEASON, C. A.; WRIGHT, E. W.; PEARL, D. K. “Time of conscious intention to act in relation to onset of cerebral activity (Readiness-Potential): The unconscious initiation of a freely voluntary act”. Brain, 106(3) (1983), p. 623-642.

LIBET, B. "Unconscious cerebral initiative and the role of conscious will in voluntary action”. The Behavioral and Brain Sciences, 8(4) (1985), p. 529-566.

LOWE, E. J. Personal agency: The metaphysics of mind and action. Oxford: Oxford University Press, 2008.

MELE, A. Effective Intentions. New York: Oxford University Press, 2009.

NAHMIAS, E. "When consciousness matters: A critical review of Daniel Wegner's the illusion of conscious will”. Philosophical Psychology, 15(4) (2002), p. 527-541.

O'SHAUGNASSEY, B. “The will”. In: GUTTENPLAN, S. (Ed.). A companion to the philosophy of mind. Oxford: Blackwell Publishers, 1996, p. 610-17.

PANKSEPP, J. "Free will and the variety of affective and cognitive selves". In: Précis of the illusion of conscious will. Behavioral and Brain Sciences, 27(5) (2004), p. 23-24.

PENFIELD, W. The mystery of mind. Princeton: Princeton University Press, 1975.

SCHLEGEL, A.; ALEXANDER, P.; SINNOTT-ARMSTRONG, W.; ROSKIES, A.; TSE, P. U.; WHEATLEY, T. "Barking up the wrong free: Readiness Potentials reflect processes independent of conscious will”. Experimental Brain Research, 229(3) (2013), p. 329-35. 
B. Marques - An issue for Wegner's theory about the conscious will | 1045

SCHURGER, A.; SITT, J. D.; DEHAENE, S. “An accumulator model for spontaneous neural activity prior to self-initiated movement”. Proceedings of the National Academy of Sciences, 109(42) (2012), p. E2904-13.

SERGENT, C.; BAILLET, S.; DEHAENE, S. "Timing of the brain events underlying access to consciousness during the attentional blink". Nature Neuroscience, 8(10) (2005), p. 1391-1400.

TREVENA, J.; MILLER, J. "Brain preparation before a voluntary action: Evidence against unconscious movement initiation”. Consciousness and Cognition, 19(1) (2010), p. $447-456$.

WEGNER, D. The illusion of conscious will. Cambridge: MIT Press, 2002.

WEGNER, D. "Self is magic". In: BAER, J.; KAUFMAN, J. C.; BAUMEISTER, R. F. (Ed.). Are we free? Psychology and free will. New York: Oxford University Press, 2008, p. 227-247. 